\title{
High-flow nasal cannula oxygenation and tocilizumab administration in patients critically ill with COVID-19: A report of three cases and a literature review
}

\author{
ANDREA MARINO $^{1}$, ALESSIO PAMPALONI $^{1}$, DANIELE SCUDERI $^{1}$, FEDERICA COSENTINO $^{1}$, \\ VITTORIA MOSCATT $^{1}$, MANUELA CECCARELLI ${ }^{1}$, MARIA GUSSIO ${ }^{1}$, BENEDETTO MAURIZIO CELESIA ${ }^{1}$, \\ ROBERTO BRUNO $^{1}$, SAVINO BORRACCINO ${ }^{2}$, GIUSEPPE NUNNARI ${ }^{3}$ and BRUNO CACOPARDO ${ }^{1}$ \\ ${ }^{1}$ Division of Infectious Diseases, Department of Clinical and Experimental Medicine; ${ }^{2}$ Unit of Intensive Care, \\ ARNAS Garibaldi Hospital, I-95122 Catania; ${ }^{3}$ Department of Clinical and Experimental Medicine, \\ Unit of Infectious Diseases, University of Messina, I-98124 Messina, Italy
}

Received 20 July, 2020; Accepted 13 August, 2020

DOI: $10.3892 /$ wasj.2020.64

\begin{abstract}
Since late 2019, SARS-CoV2 has spread worldwide, leading the WHO to declare a pandemic state. Italy was deeply affected by the virus, particularly North Italy. Several molecules have been tested for the treatment of coronavirus disease (COVID-19), comparing the treatment efficacy and collateral effects. To date, no antiviral drugs have been approved for the treatment of the COVID-19 viral phase or for the inflammatory phase. Undoubtedly, oxygen support plays a key role in the management of patients affected by this virus. The present study reports the cases of 3 patients critically ill with COVID-19. Despite antiviral therapy, their clinical conditions deteriorated a few days following admission, particularly as regards respiratory performance, together with chest X-ray findings and arterial blood gas parameters. The levels of inflammatory markers were also elevated. The patients were treated with high-flow nasal cannula (HFNC) oxygenation along with a double dose of tocilizumab. A few days following HFNC and tocilizumab administration, the respiratory rates and arterial blood gas data were ameliorated along with chest X-ray results. The use of HFNC was then slowly reduced until it was terminated, with the patients achieving a successful discharge. On the whole, as presented herein, it is indisputable more data and guidelines for COVID-19 therapies are warranted in order to guide clinicians as to the appropriate clinical treatment which will guarantee an optimal therapeutic response.
\end{abstract}

Correspondence to: Dr Andrea Marino, Division of Infectious Diseases, Department of Clinical and Experimental Medicine, ARNAS Garibaldi Hospital, Via Palermo 636, I-95122 Catania, Italy E-mail: andreamarino16@alice.it

Key words: COVID-19 pandemic, COVID-19, COVID-19 treatment

\section{Introduction}

In late 2019, a type of pneumonia of unknown origin was reported in Wuhan, China (1). The causative pathogen was then identified as a novel $\beta$-coronavirus, and was subsequently named severe acute respiratory syndrome coronavirus 2 (SARS-CoV2) $(1,2)$. Since then, there has been a rapid spread of the virus worldwide, leading the World Health Organization (WHO) to declare SARS-CoV2 outbreak a global pandemic on March 11, 2020 (3).

The majority of infected individuals who develop disease from SARS-CoV2 infection (COVID-19) exhibit a mild-to-moderate illness (80\%); however, $14 \%$ suffer from serious disease and in $6 \%$ of cases, this evolves towards a severe acute respiratory distress syndrome (ARDS), requiring intensive care support (4).

Up to the May 23, 2020, >5 million cases of SARS-CoV2 infections were reported and 340,260 individuals succumbed to the disease worldwide. To date, a total of 228,658 cases have been reported in Italy, 35,616 of which have not survived (5).

There are no proven specific antiviral agents for the treatment of COVID-19; nevertheless, several new and old molecules have been used in the context of clinical trials, while waiting for solid evidences to render drug administration safer and more precise (6).

A role has been claimed for the monoclonal antibody, tocilizumab, that blocks the cellular receptor of interleukin (IL)-6, playing a crucial role in the development and maintenance of inflammation. In addition, oxygen support plays a key role in the management of severe cases of COVID-19 (7). In that context, high-flow nasal cannula (HFNC) oxygenation may represent a promising therapeutic support option in the governance of these critically ill patients.

The present study reports the cases of 3 patients critically ill with COVID-19, confirmed by positive results of SARS-CoV2 RT-PCR on nasopharyngeal swab; the conditions of the patients markedly improved and they were successfully discharged following tocilizumab administration and HFNC treatment. 


\section{Case report}

First patient. Upon admission, the patient was feverish (temperature, $37.5^{\circ} \mathrm{C}$ ), with a blood pressure of $110 / 70 \mathrm{mmHg}$, a heart rate (HR) of $92 \mathrm{bpm}$, oxygen saturation rate of $89 \%$ in room air and a respiratory rate $(\mathrm{RR})$ of $23 / \mathrm{min}$. Blood tests revealed elevated levels of inflammatory markers along with lymphopenia (Table I). Arterial blood analysis in room air revealed a partial pressure of oxygen $\left(\mathrm{PO}_{2}\right)$ rate of $60 \mathrm{mmHg}$, a partial pressure of carbon dioxide $\left(\mathrm{PCO}_{2}\right)$ rate of $36 \mathrm{mmHg}, \mathrm{pH} 7.46$, and an arterial partial pressure of oxygen $\left(\mathrm{PaO}_{2}\right) /$ fractional inspired oxygen $\left(\mathrm{FiO}_{2}\right)$ ratio of 285 . A chest $\mathrm{X}$-ray revealed bilateral interstitial pneumonia (Fig. 1).

He was administered darunavir/cobicistat $(800+150 \mathrm{mg} /$ day $)$, hydroxychloroquine (400 mg/day, after loading dose), azithromycin $(500 \mathrm{mg} /$ day), enoxaparin (6,000 UI/day). Moreover, he was administered oxygen with a Venturi mask at $14 \mathrm{l} / \mathrm{min}$ $\left(\mathrm{FiO}_{2} 60 \%\right)$.

On the 3rd day from the time of admission, due to the worsening of RR (32/min; $\mathrm{PaO}_{2} 75 \mathrm{mmHg} ; \mathrm{PCO}_{2} 37 \mathrm{mmHg}$; $\mathrm{pH}$ 7.46; $\mathrm{PaO}_{2} / \mathrm{FiO}_{2} 126$ ), he was administered oxygen ventilation with HFNC (Optiflow ${ }^{\mathrm{TM}}$ Nasal High Flow Therapy delivered by $\mathrm{AIRVO}^{\mathrm{TM}}$ 2), $50 \mathrm{l} / \mathrm{min}, \mathrm{FiO}_{2} 50 \%$. On the same day, the patient was administered tocilizumab $8 \mathrm{mg} / \mathrm{kg}$ i.v., at 2 consecutive doses within $12 \mathrm{~h}$.

Within 2 days from tocilizumab administration, the clinical status and respiratory performances of the patient markedly improved. HFNC ventilation was continued for a further 6 days. Subsequently, HFNC treatment was slowly reduced by interchanging it with a Venturi mask for another 2 days, at which time high-flow ventilation was definitively terminated. Both arterial blood analysis and chest X-rays revealed progressive amelioration.

Second patient. Upon admission, the patient was feverish (temperature, $38.5^{\circ} \mathrm{C}$ ), blood pressure was $140 / 80 \mathrm{mmHg}$, HR was $100 \mathrm{bpm}$, oxygen saturation was $91 \%$ in room air and the RR was $24 / \mathrm{min}$. Blood tests revealed high levels of inflammatory markers along with lymphopenia (Table I). Arterial blood analysis in room air revealed $\mathrm{PaO}_{2} 50 \mathrm{mmHg}$, $\mathrm{PCO}_{2} 35 \mathrm{mmHg}$, and $\mathrm{pH} 7.44$; the $\mathrm{PaO} 2 / \mathrm{FiO} 2$ ratio was 238 . Her chest X-ray revealed bilateral ground glass areas without consolidations (Fig. 2).

The patient was administered lopinavir/ritonavir (200 mg/50 mg 4 tabs/day per os), hydroxychloroquine ( $400 \mathrm{mg} /$ day per os, after loading dose), azithromycin ( $500 \mathrm{mg} /$ day per os), ceftriaxone ( $\mathrm{gr} /$ day, i.v.) and enoxaparin (6,000 UI/day). Furthermore, she was administered oxygen support therapy with a Venturi mask $\left(12 \mathrm{l} / \mathrm{min}, \mathrm{FiO}_{2} 60 \%\right)$.

On day 2 from the time of admission, her clinical conditions began to deteriorate, with chest X-ray results worsening. She became dyspneic (RR was 30/min) and arterial blood analysis during oxygen ventilation revealed a $\mathrm{PaO}_{2}$ of $80 \mathrm{mmHg}, \mathrm{PCO}_{2}$ of $33.4 \mathrm{mmHg}$, pH $7.38(\mathrm{PaO} 2 / \mathrm{FiO} 2$ ratio was 133). She was administered $\mathrm{HFNC}$ ventilation $\left(50 \mathrm{l} / \mathrm{min}, \mathrm{FiO}_{2} 60 \%\right)$ and tocilizumab was also administered intravenously, at 2 doses of $8 \mathrm{mg} / \mathrm{kg}, 12 \mathrm{~h}$ apart.

Within $24 \mathrm{~h}$, her clinical condition began to improve with a marked improvement in the chest X-ray results. The levels of serum inflammatory markers also decreased. At 6 days following the administration of tocilizumab, HFNC treatment was slowly reduced, interchanging it with a Venturi mask every $6 \mathrm{~h}$. After 11 days, HFNC was terminated and treatment with a Venturi mask was continued until discharge.

Third patient. Upon admission, the patient was feverish $\left(37.8^{\circ} \mathrm{C}\right)$, with a blood pressure of $140 / 70 \mathrm{mmHg}$, HR of $100 \mathrm{bpm}, \mathrm{RR}$ of $25 / \mathrm{min}$ and an oxygen saturation of $90 \%$ in room air. Blood tests revealed high levels of inflammatory markers (Table I). Arterial blood analysis in room air revealed a $\mathrm{PO}_{2}$ of $53 \mathrm{mmHg}, \mathrm{PCO}_{2}$ of $37 \mathrm{mmHg}$, $\mathrm{pH} 7.45$ and a $\mathrm{PaO}_{2} / \mathrm{FiO}_{2}$ of 250 . A chest X-ray revealed bilateral interstitial pneumonia without consolidation (Fig. 3).

The patient was administered darunavir/cobicistat $(800+150 \mathrm{mg} / \mathrm{day})$, hydroxychloroquine $(400 \mathrm{mg} / \mathrm{day}$ after loading dose), azithromycin (500 mg/day), ceftriaxone ( $2 \mathrm{~g} /$ day $)$ and enoxaparin (6,000 UI/day). Furthermore, she was administered oxygen therapy with a Venturi mask at $14 \mathrm{l} / \mathrm{min}\left(\mathrm{FiO}_{2} 60 \%\right)$.

In spite of treatment, the clinical status of the patient deteriorated (on the 3rd day from the time of admission) together with a deterioration in the RR (34/min) and an extension of bilateral infiltrates on chest X-rays. Since the arterial gas analysis values worsened $\left(\mathrm{PaO}_{2} 72 \mathrm{mmHg}, \mathrm{PCO}_{2} 37 \mathrm{mmHg}\right.$, $\mathrm{pH} 7.47, \mathrm{PaO}_{2} / \mathrm{FiO}_{2}$ 120), HFNC ventilation was commenced (50 1/min, $\left.\mathrm{FiO}_{2} 60 \%\right)$ and 2 doses of tocilizumab $(8 \mathrm{mg} / \mathrm{kg})$ were administered intravenously within $12 \mathrm{~h}$.

At $36 \mathrm{~h}$ following the commencement of HFNC and tocilizumab administration, the clinical condition of the patient began to progressively improve. HFNC was terminated within 10 days, and a Venturi mask was used for 4 days. Two consecutive Chest X-rays revealed a clear-cut improvement of the bilateral interstitial infiltrative lesions.

\section{Discussion}

There are two main pathogenetic stages in the development of COVID-19. Namely, the 'viral phase' due to viral intracellular replication, including of mild symptoms (8); and an 'inflammatory phase' due to the host immune response, including severe respiratory symptoms and even ARDS with a marked increase in levels of serum inflammatory markers, known as the so-called 'cytokine storm' $(8,9)$. In each of these phases, in the cases presented herein, successful treatment intervention was achieved with different treatments.

Treatment for the viral phase has been based on the uncertain antiviral activity of certain molecules, such as lopinavir/ritonavir or darunavir/cobicistat (10), hydroxychloroquine (11) and azithromycin (12), along with enoxaparin, in prophylactic or therapeutic dosage, to treat the ipercoagulative status (13).

The Infectious Diseases Society of America (IDSA) guidelines (6) recommend the use of antiviral drugs only in the context of clinical trials, with accurate caution to the collateral effects, which may be particularly pernicious (such as QT prolongation for azithromycin and hydroxychloroquine as well as important bleeding for enoxaparin or diarrhea with lopinavir/ritonavir).

According to the clinical conditions of the patients presented herein, it was decided that they should be administered a short course of antiviral drugs and a prophylactic dose of enoxaparin. 
Table I. Demographics, clinical characteristics at the time of admission, treatment and outcomes of the 3 patients with COVID-19.

\begin{tabular}{|c|c|c|c|}
\hline Characteristics & Patient 1 & Patient 2 & Patient 3 \\
\hline Age, years & 63 & 55 & 77 \\
\hline Sex & Male & Female & Female \\
\hline Comorbidities & None & None & $\begin{array}{l}\text { COPD, hypertension, } \\
\text { hypothyroidism, } \\
\text { hypercholesterolemia }\end{array}$ \\
\hline Home therapy & None & None & $\begin{array}{c}\text { Perindopril/indapamide, } \\
\text { bisoprolol, statin, } \\
\text { levothyroxine }\end{array}$ \\
\hline Chest X-ray findings & $\begin{array}{l}\text { Bilateral interstitial } \\
\text { pneumonia }\end{array}$ & $\begin{array}{l}\text { Bilateral ground } \\
\text { glass area }\end{array}$ & $\begin{array}{l}\text { Bilateral interstitial } \\
\text { pneumonia }\end{array}$ \\
\hline $\begin{array}{l}\text { Days between the onset of symptoms and } \\
\text { hospital admission }\end{array}$ & 8 & 5 & 5 \\
\hline Symptoms on admission & $\begin{array}{l}\text { Dyspnea, fever } \\
\text { cough, headache }\end{array}$ & $\begin{array}{l}\text { Dyspnea, fever } \\
\text { cough }\end{array}$ & $\begin{array}{l}\text { Dyspnea, fever } \\
\text { cough }\end{array}$ \\
\hline \multicolumn{4}{|l|}{ Laboratory findings, unit (reference range) } \\
\hline WBC, cells/mmc $(4,000-10,000)$ & 6,800 & 8,300 & 9,500 \\
\hline Neutrophils, \% (40-75) & 78 & 83 & 74 \\
\hline Lymphocytes, \% (25-50) & 15 & 8 & 14,2 \\
\hline Monocytes, \% (2-10) & 5,8 & 8 & 1,1 \\
\hline Platelets, cells $/ \mathrm{mmc} \times 10^{3}(150-400)$ & 323 & 201 & 126 \\
\hline Hemoglobin, g/dl (12-16) & 13,6 & 11,6 & 13,4 \\
\hline AST, UI/1 (15-35) & 44 & 22 & 47 \\
\hline ALT, UI/1 (15-35) & 40 & 11 & 32 \\
\hline LDH, UI/1 (80-250) & 348 & 279 & 325 \\
\hline Creatinine, mg/dl $(0,8-1,2)$ & 0,8 & 1,2 & 0,75 \\
\hline CRP, mg/dl (0-0.5) & 6,3 & 4 & 9 \\
\hline ESR, mm/h (0-10) & 67 & 75 & 50 \\
\hline IL-6, pg/ml (<20) & 450 & 1,500 & 343 \\
\hline Ddimer, ng/ml (<250) & 1,708 & 900 & 1,675 \\
\hline Ferritin, ng/ml (20-200) & 1,300 & 2,600 & 1,572 \\
\hline Lowest $\mathrm{PaO}_{2} / \mathrm{FiO}_{2}$ ratio (126) & 133 & 120 & \\
\hline Antiviral therapy (duration) & $\begin{array}{l}\text { Darunavir/cobicistat } \\
\text { (5 days) }\end{array}$ & $\begin{array}{l}\text { Lopinavir/ritonavir } \\
\qquad \text { (5 days) }\end{array}$ & $\begin{array}{l}\text { Darunavir/cobicistat } \\
\text { (5 days) }\end{array}$ \\
\hline Antibiotic therapy (duration) & $\begin{array}{l}\text { Azythromicin } \\
\text { (10 days) }\end{array}$ & $\begin{array}{l}\text { Azythromicin ( } 7 \text { days) } \\
\text { Ceftriaxone ( } 7 \text { days) }\end{array}$ & $\begin{array}{l}\text { Azythromicin ( } 5 \text { days) } \\
\text { Ceftriaxone ( } 5 \text { days) }\end{array}$ \\
\hline Other therapies (duration) & $\begin{array}{l}\text { Hydroxycloroquine } \\
\text { (10 days), enoxaparin } \\
6,000 \text { UI s.c. ( } 24 \text { days) }\end{array}$ & $\begin{array}{l}\text { Hydroxycloroquine } \\
\text { (7 days), enoxaparin } \\
6,000 \text { UI s.c. (22 days) }\end{array}$ & $\begin{array}{l}\text { Hydroxycloroquine } \\
\text { (7 days), enoxaparin } \\
6,000 \text { UI s.c. (18 days) }\end{array}$ \\
\hline Days on HFNC & 8 & 11 & 10 \\
\hline Tocilizumab dose & $8 \mathrm{mg} / \mathrm{kg}$ (2 doses) & $8 \mathrm{mg} / \mathrm{kg}(2$ doses $)$ & $8 \mathrm{mg} / \mathrm{kg}$ (2 doses) \\
\hline Days from admission to tocilizumab & 3 & 2 & 3 \\
\hline Time to hospital discharge (days) & 24 & 22 & 18 \\
\hline
\end{tabular}

COPD, chronic obstructive pulmonary disease; WBC, white blood cell count; AST, aspartate aminotransferase; ALT, alanine aminotransferase; LDH, lactate dehydrogenase; CRP, C-reactive protein; ESR, erythrocyte sedimentation rate; IL-6, interleukin 6; HFNC, high-flow nasal cannula.

They exhibited no adverse drug reactions. Moreover, QTc daily was assessed without any evidence of prolongation.
IL-6 is a relevant marker of inflammation implicated in the COVID-19 cytokine burst. The IL-6 level can assist clinicians 

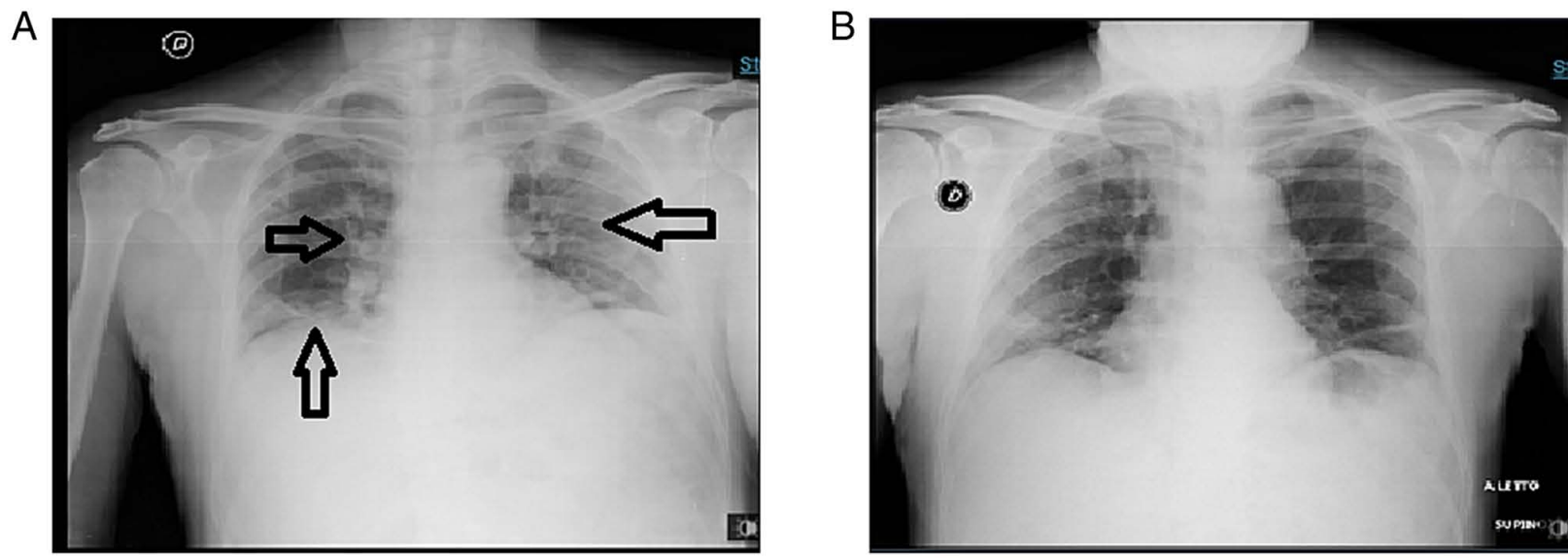

Figure 1. Chest X-ray results of the first patient in the present case series at (A) the time of admission and (B) upon improvement/discharge. Arrows indicate pathogenic lesions.
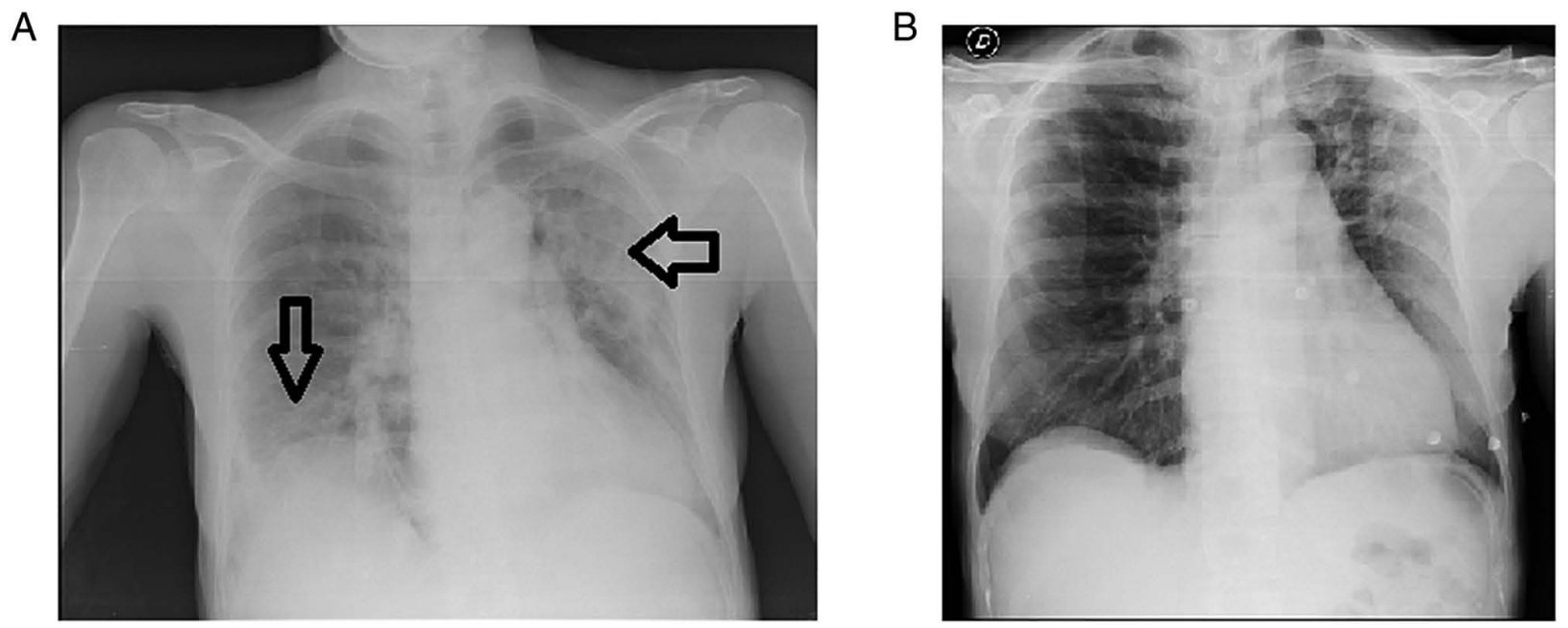

Figure 2. Chest X-ray results of the second patient in the present case series at (A) the time of admission and (B) upon improvement/discharge. Arrows indicate pathogenic lesions.
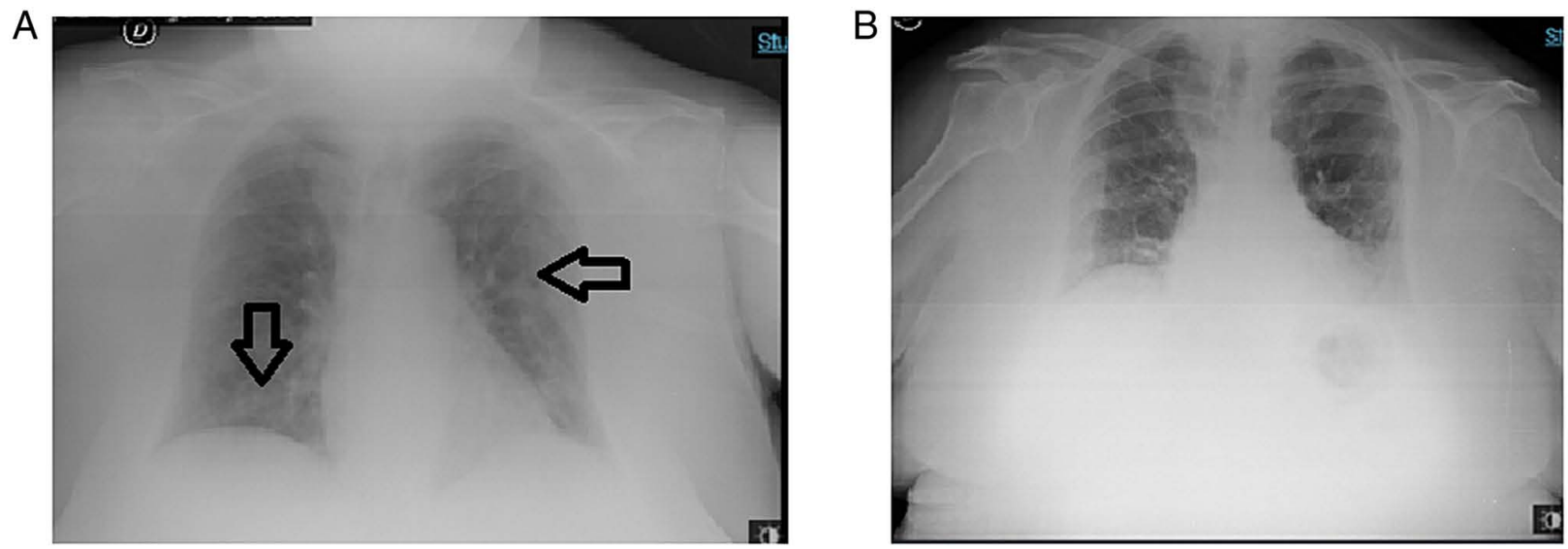

Figure 3. Chest X-ray results of the third patient in the present case series at (A) the time of admission and (B) upon improvement/discharge. Arrows indicate pathogenic lesions.

in recognizing patients with a major risk of severe disease progression (14). Tocilizumab, which is a recombinant monoclonal antibody targeting the IL-6 receptor, has been already used in the treatment of rheumatoid arthritis and Crohn's disease (15). To date, only a small group of patients or simple studies have reported the use of tocilizumab in the treatment of 
patients with severe COVID-19 infection, achieving promising clinical results $(15,16)$.

Tocilizumab can be used in patients with extensive bilateral lung involvements or in patients with severe/critical illness, with elevated levels of serum IL-6. The dose is $8 \mathrm{mg} / \mathrm{kg}$ i.v., diluted in $100 \mathrm{ml}$ of $0.9 \%$ saline solution. For patients with a poor clinical response, a second dose could be administered after 8-12 h (17).

In the cases presented herein, two $8 \mathrm{mg} / \mathrm{kg}$ tocilizumab doses were administered intravenously, $12 \mathrm{~h}$ apart. The patients did not exhibit any adverse drug reactions. Prior to the tocilizumab administration, the hepatitis B virus (HBV) status of the patients was assessed and latent tuberculosis infection was excluded by specific interferon (IFN)- $\gamma$ assay. Repeated chest X-rays revealed the progressive reabsorption of interstitial exudation in all cases.

High-flow oxygen systems (such as HFNC) provide heated, oxygen-rich, humidified gas to the patient at flow levels sufficient to deliver a constant, precisely set high $\mathrm{FiO}_{2}$ (7). HFNC flow rates reach up to $60 \mathrm{l} / \mathrm{min}$, reducing the pulmonary dead space, providing low levels of positive end-expiratory pressure (PEEP), and decreasing breathing frequency and effort (18). The use of HFNC is associated with a lower mortality rate in hypoxemic respiratory failure (19). Compared to non-invasive ventilation (NIV) oxygen therapy, HFNC is associated with a decreased need of subsequent intubation and ICU admission $(20,21)$, and with a lower risk of 30-day mortality in patients with pneumonia (22).

Moreover, patients have found HFNC to be more comfortable and better tolerated than NIV and the management of HFNC is relatively easier (23). In a retrospective study of 610 COVID19-positive patients from China, where $10 \%$ of the affected patients required critical care, an early use of HFNC was associated with a reduced necessity of mechanical ventilation and a lower mortality rate (24). Furthermore, HFNC has been shown to be associated with a significantly lower risk of bioaerosol dispersion, reducing the risk of hospital-acquired infections for health workers (25).

Following HFNC ventilation, the patients in the present study achieved a marked improvement in respiratory function, as well as lower respiratory fatigue, with better results on arterial gas analysis. Teh initial approach included 24-h HFNC, and this was then interchanged with a Venturi mask (every $6 \mathrm{~h}$ ) to avoid sudden interruption.

It should be noted that it is probable that the cases presented herein were successfully influenced by the age of the patients (they were not that elderly) and as regards the first 2 patients, by the absence of comorbidities. Moreover, their admission occurred only a few days following the onset of symptoms and the level of lymphopenia was not so severe, whereas their IL-6 levels were considerably elevated. All patients were discharged with 2 negative results RT-PCR for SARS-CoV2 on a nasopharyngeal swab.

In conclusion, SARS-CoV2 infection arrived 'out of the blue' for the entire world, even in Italy. In Sicily, in South Italy, inhabitants were warned by what had already occurred in North Italy. Moreover, lockdown measures and therapeutic experiences coming from more affected areas greatly assisted the condition.

On the whole, as demonstrated herein, COVID-19-postitive patients progressing towards a more severe course may benefit from the synergistic effects of treatment with intravenously administered tocilizumab and oxygen ventilation with HFNC. Herein, 3 cases are reported, which progressed towards a marked amelioration and resolution of the disease following treatment with such a combination.

As far as was currently known up to the time of the preparation of this manuscript, to the best of our knowledge, the presently reported case series is the first to focus on the synergistic efficacy of the combined use of tocilizumab and HFNC. However, extensive randomized controlled trials (RCTs) are warranted in order to confirm the beneficial effects of such treatments and to standardize indications and timing.

\section{Acknowledgements}

The authors would like to thank Dr Pietro Leanza for his kind English revision of the manuscript.

\section{Funding}

No funding was received.

\section{Availability of data and materials}

Data sharing is not applicable to this article as no datasets were generated or analyzed during the current study.

\section{Authors' contributions}

All authors (AM, AP, DS, FC, VM, MC, MG, BMC, RB, SB, GN and BC) contributed to the study conception and design. AM wrote the manuscript. AP, DS, FC, VM and SB revised the literature and references. $\mathrm{MG}, \mathrm{BMC}$ and $\mathrm{MC}$ provided clinical assistance to the patients. $\mathrm{RB}$ was responsible for the laboratory tests and pharmacological treatments. GN and $\mathrm{BC}$ revised the manuscript. All authors read and approved the final manuscript.

\section{Ethics approval and consent to participate}

Informed consent was obtained from all individual participants included in the present case series.

\section{Patient consent for publication}

Written informed consent was obtained from the patient for publication of this case report and accompanying images.

\section{Competing interests}

The authors declare that they have no competing interests.

\section{References}

1. Zhu N, Zhang D, Wang W, Li X, Yang B, Song J, Zhao X, Huang B, Shi W, Lu R, et al: A novel coronavirus from patients with pneumonia in China, 2019. N Engl J Med 382: 727-733, 2020.

2. WHO.Coronavirus(COVID-19)eventsastheyhappen.https://www. who.int/emergencies/diseases/novel-coronavirus-2019/events-asthey-happen. 2020. Access date, April 26, 2020. 
3. WHO: Events as they happen. Rolling updates on coronavirus disease (COVID-19). WHO, 2020.

4. Wang D, Hu B, Hu C, Zhu F, Liu X, Zhang J, Wang B, Xiang H, Cheng Z, Xiong Y, et al: Clinical characteristics of 138 hospitalized patients with 2019 novel coronavirus-infected pneumonia in Wuhan, China. JAMA 323: 1061-1069, 2020.

5. RiccardoF, Ajelli M, Andrianou X, Bella A,Del Manso M,Fabian M, Bellino S, Boros S, Urdiales AM, et al: Epidemiological characteristics of COVID-19 cases in Italy and estimates of the reproductive numbers one month into the epidemic. medRxiv, 2020. doi: https://doi.org/10.1101/2020.04.08.20056861.

6. Bhimraj A, Morgan RL, Shumaker AH, Lavergne V, Baden L, Cheng VC, Edwards KM, Gandhi R, Muller WJ, O'Horo JC, et al: Infectious diseases society of America Guidelines on the Treatment and Management of Patients with COVID-19. Clin Infect Dis Apr: Apr 27 doi: 10.1093/cid/ciaa478 (Epub ahead of print).

7. Whittle JS, Pavlov I, Sacchetti AD, Atwood C and Rosenberg MS: Respiratory support for adult patients with COVID-19. J Am Coll Emerg Physicians Open: Apr 2020 doi: 10.1002/emp2.12071.

8. Shi Y, Wang Y, Shao C, Huang J, Gan J, Huang X, Bucci E, Piacentini M, Ippolito G and Melino G: COVID-19 infection: The perspectives on immune responses. Cell Death Differ 27: 1451-1454, 2020

9. Marino A, Cosentino F, Pampaloni A, Scuderi D, Moscatt V, Gussio M, Onorante A, Zagami A, Torrisi S, Grasso S, et al: Role of tocilizumab and high flow nasal cannula in the clinical management of severe Covid-19. J Clin Trials 10: 427, 2020.

10. Cao B, Wang Y, Wen D, Liu W, Wang J, Fan G, Ruan L, Song B, Cai Y, Wei M, et al: A Trial of lopinavir-ritonavir in adults hospitalized with severe covid-19. N Engl J Med 382: 1787-1799, 2020 .

11. Taccone FS, Gorham J and Vincent JL: Hydroxychloroquine in the management of critically ill patients with COVID-19: The need for an evidence base. Lancet Respir Med 8: 539-541, 2020.

12. Felsenstein S, Herbert JA, McNamara PS and Hedrich CM COVID-19: Immunology and treatment options. Clin Immunol [Internet]. 2020/04/27. 2020 Jun; 215:108448. Available from: https://www.ncbi.nlm.nih.gov/pmc/articles/PMC7185015/.

13. Cattaneo M, Bertinato EM, Birocchi S, Brizio C, Malavolta D, Manzoni M, Muscarella G and Orlandi M: Pulmonary embolism or pulmonary thrombosis in COVID-19? Is the recommendation to use high-dose heparin for thromboprophylaxis justified? Thromb Haemost 120: 1230-1232, 2020.

14. Aziz M, Aziz M, Fatima R and Assaly R: Elevated Interleukin-6 and Severe COVID-19: A meta-analysis. Med Virol: 28 April, 2020 https://doi.org/10.1002/jmv.25948.
15. Zhang C, Wu Z, Li JW, Zhao $\mathrm{H}$ and Wang GQ: The cytokine release syndrome (CRS) of severe COVID-19 and Interleukin-6 receptor (IL-6R) antagonist Tocilizumab may be the key to reduce the mortality. Int J Antimicrob Agents 55: 105954, 2020.

16. Luo P, Liu Y, Qiu L, Liu X, Liu D and Li J: Tocilizumab treatment in COVID-19: A single center experience. J Med Virol: 6 April, 2020 https://doi.org/10.1002/jmv.25801.

17. Fu B, Xu X and Wei $\mathrm{H}$ : Why tocilizumab could be an effective treatment for severe COVID-19? J Trans Med 18: 164, 2020.

18. Nishimura M: High-flow nasal cannula oxygen therapy in adults. J Intensive Care 3: 15, 2015.

19. Frat JP, Thille AW, Mercat A, Girault C, Ragot S, Perbet S, Prat G, Boulain T, Morawiec E, Cottereau A, et al: High-flow oxygen through nasal cannula in acute hypoxemic respiratory failure. N Engl J Med 372: 2185-2196, 2015.

20. Rochwerg B, Granton D, Wang DX, Helviz Y, Einav S, Frat JP, Mekontso-Dessap A, Schreiber A, Azoulay E, Mercat A, et al: High flow nasal cannula compared with conventional oxygen therapy for acute hypoxemic respiratory failure: A systematic review and meta-analysis. Intensive Care Med 45: 563-572, 2019.

21. Nagata K, Morimoto T, Fujimoto D, Otoshi T, Nakagawa A Otsuka K, Seo R, Atsumi T and Tomii K: Efficacy of high-flow nasal Cannula therapy in acute hypoxemic respiratory failure: Decreased use of mechanical ventilation. Respir Care 60: 1390-1396, 2015

22. Koga Y, Kaneda K, Fujii N, Tanaka R, Miyauchi T, Fujita M, Hidaka K, Oda Y and Tsuruta R: Comparison of high-flow nasal cannula oxygen therapy and non-invasive ventilation as first-line therapy in respiratory failure: A multicenter retrospective study. Acute Med Surg 7: e461, 2019.

23. Wang K, Zhao W, Li J, Shu W and Duan J: The experience of high-flow nasal cannula in hospitalized patients with 2019 novel coronavirus-infected pneumonia in two hospitals of Chongqing, China. Ann Intensive Care 10: 37, 2020.

24. Guan WJ, Ni ZY, Hu Y, Liang WH, Ou CQ, He JX, Liu L, Shan H, Lei CL, Hui DSC, et al: Clinical characteristics of coronavirus disease 2019 in China. N Engl J Med 382: 1708-1720, 2020.

25. Li J, Fink JB and Ehrmann S: High-flow nasal cannula for COVID-19 patients: Low risk of bio-aerosol dispersion. Eur Respir J 55: 2000892, 2020.

This work is licensed under a Creative Commons Attribution-NonCommercial-NoDerivatives 4.0 International (CC BY-NC-ND 4.0) License. 